\title{
Value analysis of digital breast tomosynthesis for breast cancer screening in a commercially-insured US population
}

This article was published in the following Dove Press journal:

ClinicoEconomics and Outcomes Research

12 January 2015

Number of times this article has been viewed

\author{
Machaon M Bonafede' \\ Vivek B Kalra ${ }^{2}$ \\ Jeffrey D Miller' \\ Laurie L Fajardo ${ }^{3}$ \\ 'Truven Health Analytics, Cambridge, \\ MA, ${ }^{2}$ Yale University School \\ of Medicine, New Haven, CT, \\ ${ }^{3}$ Department of Radiology, University \\ of lowa College of Medicine, lowa \\ City, IA, USA
}

Purpose: The objective of this study was to conduct a value analysis of digital breast tomosynthesis (DBT) for breast cancer screening among women enrolled in US commercial health insurance plans to assess the potential budget impact associated with the clinical benefits of DBT.

Methods: An economic model was developed to estimate the system-wide financial impact of DBT as a breast cancer screening modality within a hypothetical US managed care plan with one million members. Two scenarios were considered for women in the health plan who undergo annual screening mammography, ie, full field digital mammography (FFDM) and combined FFDM + DBT. The model focused on two main drivers of DBT value, ie, the capacity for DBT to reduce the number of women recalled for additional follow-up imaging and diagnostic services and the capacity of DBT to facilitate earlier diagnosis of cancer at less invasive stages where treatment costs are lower. Model inputs were derived from published sources and from analyses of the Truven Health MarketScan ${ }^{\circledR}$ Research Databases (2010-2012). Comparative clinical and economic outcomes were simulated for one year following screening and compared on an incremental basis.

Results: Base-case analysis results show that 4,523 women in the hypothetical million member health plan who are screened using DBT avoid the use of follow-up services. The overall benefit of DBT was calculated at $\$ 78.53$ per woman screened. Adjusting for a hypothetical $\$ 50$ incremental cost of the DBT examination, this translates to $\$ 28.53$ savings per woman screened, or $\$ 0.20$ savings per member per month across the plan population and an overall cost savings to the plan of $\$ 2.4$ million per year.

Conclusion: The results of this study demonstrate clinical and economic favorability of DBT for breast cancer screening among commercially-insured US women. Wider adoption of DBT mammography presents an opportunity to deliver value-based care in the US health care system.

Keywords: breast cancer screening, mammography, digital breast tomosynthesis, cost analysis, value analysis, economic model

\section{Introduction}

Breast cancer is the most common cancer among women, accounting for $29 \%$ of newly diagnosed cancers, and is the second most common cause of death from cancer in women in the USA. ${ }^{1-3}$ In 2014, an estimated 232,670 new cases of invasive breast cancer will be diagnosed among women, as well as an estimated 62,570 cases of ductal carcinoma in situ. ${ }^{1-3}$ Also in 2014, approximately 40,000 women are expected to die from breast cancer. ${ }^{1-3}$ Despite increasing incidence rates, annual mortality rates from breast cancer have declined by approximately $2 \%$ per year, ${ }^{1-3}$ which has been attributed
Correspondence: Jeffrey D Miller Truven Health Analytics, I50 Cambridge Park Drive, 2nd Floor, Cambridge, MA 02140, USA

Tel +l 9787603886

Email jeffrey.d.miller@truvenhealth.com 
to the combination of earlier detection using screening mammography and improvements in treatment., ${ }^{4,5}$

Current guidelines for the early detection of breast cancer published by the American Cancer Society (ACS) and American College of Obstetricians and Gynecologists advocate for annual mammography beginning at age 40 years..$^{3,6,7}$ The ACS also recommends that women should have an opportunity to become informed about the benefits, limitations, and potential harms associated with regular screening. ${ }^{3,8}$

An abnormal finding with screening mammography prompts additional imaging with diagnostic mammography or mammography consisting of additional views (eg, magnification, spot compression, and new angles), a targeted breast ultrasound, or breast magnetic resonance imaging., ${ }^{9,10}$ These additional imaging studies help determine the need for tissue sampling (ie, biopsy) in order to determine if the area of concern is benign or malignant. ${ }^{9}$ Due to the relatively low positive predictive value of traditional screening mammography, a considerable percentage of women called back for additional imaging or biopsy do not ultimately have cancer (ie, a false-positive test result), resulting in unnecessary patient anxiety and economic burden. ${ }^{8,11,12}$ To guide improved quality standards, the American College of Radiology (ACR) and the Agency for Healthcare Research and Quality (AHRQ) advocate as a benchmark that the percentage of women recalled after screening mammography should be $10 \%$ or less. ${ }^{13-15}$ However, real-world rates for recall vary considerably. ${ }^{13-15}$ A recent review of 52 institutions reported that one in four facilities experience a recall rate greater than $14 \%{ }^{16}$

Two-dimensional digital mammography is the current standard of care in breast cancer screening. Three-dimensional mammography (referred to in this paper as digital breast tomosynthesis, or DBT) is a technological advancement of mammography over two-dimensional digital mammography. ${ }^{11,17}$ In February 2011, the Selenia ${ }^{\circledR}$ Dimensions $^{\circledR}$ breast tomosynthesis system (Hologic, Inc., Marlborough, MA, USA) was the first commercial system approved by the US Food and Drug Administration for the same clinical indications as two-dimensional full field digital mammography (FFDM). ${ }^{17-19}$ The unit can be used for standard FFDM imaging or combination FFDM + DBT imaging. ${ }^{17,18}$ Operationally, DBT acquires low-dose X-ray images from multiple angles during a short scan, reconstructs the images into a series of high-resolution "slices", and then displays them individually or in a dynamic three-dimensional ciné mode. ${ }^{17,19}$ DBT reduces challenges due to overlapping structures in breast tissue associated with twodimensional mammography. ${ }^{17,18,20}$ DBT increases lesion and margin visibility and helps to localize structures in the breast, all of which leads to increased cancer detection and reduced false-positive recalls. ${ }^{17}$ Publications of breast cancer screening performed using DBT have demonstrated reductions in recall between $15 \%$ and $37 \%$ and an accompanying increase in invasive cancer detection of $10 \%-54 \% .^{21-27}$

While the clinical advantages of DBT are fairly well understood and are growing to be appreciated by a wide audience of health care providers and payers, the economic aspects of DBT have only begun to be formally evaluated..$^{28,29}$ Within the growing cost-conscious health care environment, a better understanding regarding the clinical and economic value of DBT would help to inform sound decision-making by health care providers and managed care payers responsible for mammography screening. ${ }^{30}$ The objective of this study was to conduct a value analysis of DBT for breast cancer screening among women enrolled in US commercial health insurance plans to assess its clinical benefits, associated expenditures, and net budget impact.

\section{Materials and methods Economic model overview}

An economic model was developed to estimate the systemwide financial impact of DBT as a breast cancer screening modality within a hypothetical US managed care plan with one million members. To delineate the impact and value of DBT, two screening mammography scenarios were considered for all eligible women in the health plan who undergo annual breast cancer screening mammography: FFDM used as the screening modality and FFDM + DBT used as the screening modality. Within these two scenarios (FFDM and FFDM + DBT), clinical and economic outcomes were simulated for one year following screening and compared on an incremental basis. The differences between the two scenarios represent the value of DBT, and this is expressed through a variety of metrics commonly used by health care decision-makers.

The scenarios described here are hypothetical but are intended to realistically evaluate what would happen if a health plan were to fully adopt FFDM + DBT as the primary modality for mammography screening. The primary driver of DBT economic value comes from the capacity of DBT to reduce the number of women who are recalled for additional follow-up imaging and diagnostic testing services, and the corresponding reduction in the costs of using these health care resources. A secondary driver of DBT economic value is the capacity of DBT to facilitate earlier diagnosis of cancer, particularly diagnosis of cancers at less invasive stages when treatment costs are 
lower. Together, these value drivers serve to offset additional reimbursement costs of DBT and produce a net cost savings for the hypothetical health plan under consideration.

\section{Model inputs}

\section{Data sources}

Parameter inputs and data sources for the economic model are summarized in Table 1. These values served as the default base-case parameters for the model, although the model was designed with extensive flexibility to accommodate variations and perform customized analyses specified by the model user. In general, data for the model were derived from published literature and from an analysis of two Truven Health Analytics MarketScan ${ }^{\circledR}$ Research Databases: ${ }^{31,32}$

- Truven Health Analytics MarketScan Commercial Claims and Encounters Database, which contains medical and prescription data on approximately 35 million US employees annually and their dependants with employersponsored private health insurance.

- Truven Health Analytics MarketScan Medicare Supplemental Database, which contains medical and prescription data on approximately 3 million retirees annually with Medicare supplemental (or Medigap) insurance paid for by employers. It includes the Medicare-covered portion of payment (Coordination of Benefits Amount) and the employer-paid portion. Medicare supplemental insurance typically covers copayments, coinsurance, and deductibles not covered by traditional Medicare plans.

All cost inputs in the analyses were adjusted, where necessary, to 2013 US dollars using the Medical Care component of the US Consumer Price Index.

\section{Patient population}

The Truven Health MarketScan Commercial and Medicare Supplemental Databases were analyzed over for a 3-year (2010-2012) period to identify women aged 40-75 years undergoing screening mammography. ${ }^{31,32}$ The mammography screening (ie, the index event) was defined by Healthcare Common Procedure Coding System Code G0202. Women were required to have 12 months pre-index and 6 months post-index continuous enrollment in the claims database. Women with any breast cancer screening imaging procedure or a breast cancer diagnosis in the 12-month pre-index period were excluded.

\section{Screening costs}

The FFDM screening cost was derived from the claims database analyses and estimated to be $\$ 192.50$, which includes
$\$ 164.51$ from the mammography portion and $\$ 27.99$ from the associated computer-aided detection portion. ${ }^{32}$ At the time the model was developed and the analyses were conducted (July 2014), a Current Procedural Terminology (CPT) code for screening DBT was announced, but its reimbursement rate had not been established. Therefore, the total screening cost for FFDM + DBT in the model was estimated to be $\$ 242.50$, which is $\$ 50$ higher than the current reimbursement rate for FFDM (Table 1). ${ }^{33}$

\section{Follow-up services rates}

The traditional clinical definition of "recall rate" is determined using Breast Imaging Reporting and Data System (BI-RADS) scores to determine the percentage of women recommended for additional diagnostic procedures following an abnormal or inconclusive screening mammogram. ${ }^{34}$ As our claims database does not contain BI-RADS information, we modified the scope of this definition to be inclusive of all follow-up services directly consequent to the original mammogram, referred to hereon as "follow-up services". Thus, the rate of women utilizing follow-up imaging was estimated by identifying women who received a diagnostic mammogram (Healthcare Common Procedure Coding System codes G0204 or G0206, and CPT codes 77055 or 77056) or a breast ultrasound procedure (CPT code 76645) in the 6 months following the index screen.

For the purposes of the analyses reported here, the corresponding follow-up services rate for FFDM + DBT was set at $10.00 \%$ to correspond with the ACR and AHRQ benchmark of $\leq 10 \%$ women recalled after screening mammography. ${ }^{13-15}$ As several studies have demonstrated that recall rates below $10 \%$ are achievable with DBT + FFDM, a sensitivity analysis was conducted using rates of follow-up services in the range of $8 \%-12 \%$ and the results are described alongside the basecase results. $^{21-25,27}$

\section{Follow-up services costs}

Costs of follow-up services were calculated among women with a diagnostic mammogram or breast ultrasound in the 6 months following their index screening mammogram. Follow-up service costs were the sum of: breast-related imaging procedures in the 6 months following the index screen; breast-related biopsy procedures and related expenses (eg, anesthesiology and pathology); and outpatient office visits with an abnormal or inconclusive mammogram diagnosis code or a breast-related diagnosis. Follow-up services costs were assumed to occur within the 6-month period following the index mammogram; costs in the remaining 6 months of the year were not included as they could represent utilization associated with a subsequent 
Table I Model input parameters

\begin{tabular}{|c|c|c|}
\hline Model parameter & Parameter value & Source \\
\hline \multicolumn{3}{|l|}{ Analysis population } \\
\hline Health plan size & $1,000,000$ & Assumption; typical health plan size \\
\hline \multicolumn{3}{|l|}{ (women) aged $40-75$ years } \\
\hline $\begin{array}{l}\text { Percentage of women aged } 40-75 \text { years } \\
\text { who undergo FFDM screening each year }\end{array}$ & $35.51 \%$ & Truven Health Analytics, ${ }^{31}$ Bonafede et a $\left.\right|^{32}$ \\
\hline Proportion of patients switched from & $100 \%$ & Assumption \\
\hline \multicolumn{3}{|l|}{ FFDM to FFDM + DBT screening modality } \\
\hline \multicolumn{3}{|l|}{ Follow-up services rates } \\
\hline \multicolumn{3}{|l|}{ With diagnostic mammogram or breast ultrasound } \\
\hline \multicolumn{3}{|l|}{ in the 6 months post-index screen } \\
\hline FFDM & $15.35 \%$ & Truven Health Analytics, ${ }^{31}$ Bonafede et $a^{32}$ \\
\hline $\mathrm{FFDM}+\mathrm{DBT}$ & $10.00 \%(9.00 \%-12.00 \%)$ & Baseline assumption (range) \\
\hline \multicolumn{3}{|l|}{ Cancer detection and staging } \\
\hline $\begin{array}{l}\text { Percentage of patients screened who have } \\
\text { breast cancer detected }\end{array}$ & $0.465 \%$ & Truven Health Analytics, ${ }^{31}$ Bonafede et a $\left.\right|^{32}$ \\
\hline \multicolumn{3}{|l|}{ Stage distribution of cancers detected } \\
\hline FFDM & & Partridge et al,,$^{35}$ American Cancer Society, ${ }^{5}$ \\
\hline Stage 0 (DCIS/LCIS) & $27.9 \%$ & Skaane et $\mathrm{al}^{36}$ \\
\hline Stage I & $32.9 \%$ & \\
\hline Stage 2 & $27.8 \%$ & \\
\hline Stage 3 & $8.6 \%$ & \\
\hline Stage 4 & $2.7 \%$ & \\
\hline \multicolumn{3}{|l|}{ FFDM + DBT } \\
\hline Stage 0 (DCIS/LCIS) & $27.9 \%$ & \\
\hline Stage I & $40.1 \%$ & \\
\hline Stage 2 & $22.7 \%$ & \\
\hline Stage 3 & $7.0 \%$ & \\
\hline Stage 4 & $2.2 \%$ & \\
\hline \multicolumn{3}{|l|}{ Costs } \\
\hline \multicolumn{3}{|l|}{ Screening costs, per patient (including CAD fee) } \\
\hline FFDM & $\$ 192.50$ & Truven Health Analytics, ${ }^{31}$ Bonafede et $\mathrm{al}^{32}$ \\
\hline $\mathrm{FFDB}+\mathrm{DBT}$ & $\$ 242.50$ & Assumption; FFDM cost plus $\$ 50$ \\
\hline $\begin{array}{l}\text { Follow-up services costs in year following } \\
\text { diagnosis (per patient) }\end{array}$ & $\$ 1,205.29$ & Truven Health Analytics ${ }^{31}$ \\
\hline One-year, post-diagnosis breast cancer costs by stage & & Truven Health Analytics, ${ }^{31}$ Mittmann et al, ${ }^{37}$ \\
\hline Stage 0 (DCIS/LCIS) & $\$ 35,462$ & Legorreta et al, ${ }^{38}$ Lindfors et al ${ }^{39}$ \\
\hline Stage I & $\$ 43,530$ & \\
\hline Stage 2 & $\$ 66,472$ & \\
\hline Stage 3 & $\$ 103,800$ & \\
\hline Stage 4 & $\$ 223,568$ & \\
\hline
\end{tabular}

Abbreviations: CAD, computer-aided detection; DBT, digital breast tomosynthesis; DCIS, ductal carcinoma in situ; FFDM, full field digital mammography; LCIS, lobular carcinoma in situ.

screening event. A detailed breakdown of the derivation of costs is shown in the database analysis results in Table 2. Breast cancer treatment costs were not included, nor were patient payments (eg, copayment or coinsurance).

\section{Cancer detection and staging}

The cancer detection rate was identified using the administrative claims and defined as the number of women with two breast cancer claims at least 30 days apart during the
6 months following the index screening event; ancillary or laboratory claims alone were not sufficient to establish new cancer cases.

Under the FFDM scenario, the stage of breast cancer diagnosis was distributed according to data from a study of 19,373 women with newly diagnosed stage 1, 2, 3, or 4 (American Joint Committee on Cancer Staging Manual, Fifth and Sixth Editions) breast cancer who received their primary cancer care at eight National Comprehensive Cancer Network 
Table 2 Cost estimation for follow-up services

\begin{tabular}{llll}
\hline Diagnostic service & $\begin{array}{l}\text { Mean, per patient } \\
\text { unit cost }\end{array}$ & $\begin{array}{l}\text { Utilization by patients } \\
\text { with follow-ups (\%) }\end{array}$ & $\begin{array}{l}\text { Cost (weighted } \\
\text { for utilization) }\end{array}$ \\
\hline Diagnostic mammography & $\$ 187$ & $80.45 \%$ & $\$ 150.67$ \\
Ultrasound & $\$ 233$ & $65.77 \%$ & $\$ 152.96$ \\
Outpatient office visit with breast-related diagnosis & $\$ 270$ & $23.54 \%$ & $\$ 63.50$ \\
Computer-aided detection (excluding index screening day) & $\$ 30$ & $39.98 \%$ & $\$ 11.87$ \\
Guided biopsy (including pathology and image guidance costs) & $\$ 3,413$ & $16.85 \%$ & $\$ 575.28$ \\
Open biopsy (including pathology and anesthesia costs) & $\$ 4,522$ & $4.55 \%$ & $\$ 205.74$ \\
Magnetic resonance imaging & $\$ 1,108$ & $2.96 \%$ & $\$ 32.83$ \\
Fine needle aspiration & $\$ 649$ & $1.90 \%$ & $\$ 12.33$ \\
Ductogram & $\$ 196$ & $<0.1 \%$ & $\$ 0.09$ \\
Total & & & $\$ 1,205.29$
\end{tabular}

Note: All data derived from the Truven Health Analytics MarketScan ${ }^{\circledR}$ Research Databases. ${ }^{31}$

centers in January 2000 to December $2007 .{ }^{35}$ The distribution was adjusted to include women with stage 0 breast cancer (ie, ductal carcinoma in situ or lobular carcinoma in situ) using statistical data about the ratio of stage 0 breast cancer incidence to the overall incidence of invasive cancer (ie, $27.9 \%$ of all stage $0-4$ cancers are stage 0 at diagnosis, see Table 1). ${ }^{5}$

Under the FFDM + DBT scenario, the downward shift in distribution of diagnosis of breast cancer was derived from a prospective trial comparing FFDM and FFDM + DBT in a population-based screening program using independent double reading with arbitration. ${ }^{36} \mathrm{~A}$ total of 12,621 women were included in the analysis. A fixed percentage (18.3\%) shift in stage-diagnosis (ie, from stage 2-4 to stage 1) was estimated according to node negative/positive cancers detected using FFDM versus FFDM + DBT. As shown in Table 1, and as implemented in the model, $18.3 \%$ fewer stage $2-4$ cancers were detected in the FFDM + DBT scenario, but compensated in the distribution by $21.9 \%$ more cancers diagnosed in stage 1. Stage 0 was assumed to remain constant based on reported trial results comparing FFDM with FFDM + DBT. ${ }^{27}$

\section{Post-diagnosis cancer treatment costs}

One-year, post-diagnosis breast cancer treatment costs were estimated by stage in a step-wise procedure. First, the mean total health plan cost of a newly diagnosed breast cancer patient in the year following diagnosis was derived from the administrative claims data. This value was distributed across stages 1-4 using the same stage distribution of breast cancer costs as presented in a study of the costs for women with newly-diagnosed breast cancer by disease stage, and matched to noncancer controls. ${ }^{37}$ From this study, stage 1 costs were $25.7 \%$ less than the mean overall cost, while costs for stages 2,3 , and 4 were $13.4 \%, 77.1 \%$, and $281.4 \%$ higher than the mean overall cost. These values were applied to the overall estimate from the claims database analyses to yield the cost distribution by stage shown in Table 1 . Stage 0 costs were similarly estimated using the percentage difference between stage 0 and stage 1 costs derived from a 4-year longitudinal study in a US health maintenance organization population, ${ }^{38}$ which was later adapted for use in a cost-effectiveness study of computer-aided detection screening mammography. ${ }^{39}$ The difference (ie, stage 0 was $18.5 \%$ less than stage 1) was applied to the stage 1 estimate derived above to yield a stage 0 cost (Table 1).

\section{Model outputs}

A variety of informative outputs are generated by the model. The model calculates the number of women in the health plan requiring follow-up services after their index screening mammography in the FFDM and FFDM + DBT scenarios, respectively. The incremental difference (ie, FFDM versus FFDM + DBT) represents the impact of DBT on use of follow-up services. Cost outcomes are calculated similarly. Total 1-year, plan-wide costs (comprising screening costs, follow-up services costs, and breast cancer treatment costs) are calculated for the FFDM and FFDM + DBT scenarios, respectively. Again, the incremental difference represents the impact of DBT. An identical set of cost calculations is performed and expressed on a per patient basis. Finally, the cost calculations are expressed in terms of total and incremental costs on a per member per month basis.

\section{Results}

\section{Database analysis results}

Results from the database analysis can be found in Table 1 . Annual screening rates among women aged $40-75$ years increased modestly from 2010 (34.87\%) to 2012 (36.12\%) 
for an average annual screening rate of $35.51 \%$ (Table 1 ). A total of 1,521,667 women (mean age 50.7 years) met the study inclusion criteria to evaluate follow-up service utilization and costs. The age of the women included in the study was distributed as follows: $40.9 \%$, age 40-49 years; $39.8 \%$, age 50-59 years; $17.6 \%$, age 60-69 years; and $1.6 \%$, age $70-75$ years. Of these women, 233,543 (15.35\%) had an additional imaging procedure (diagnostic mammogram or breast ultrasound) in the 6 months post-index and was set as the model base-case FFDM follow-up services rate (Table 1). Overall costs of follow-up services in the 6 months following an abnormal or inconclusive mammogram were derived from the claims database analyses and estimated to be $\$ 1,205.29$ (Table 1). Overall, 4.65 per 1,000 (ie, $0.465 \%$ ) screened women were newly diagnosed with breast cancer (Table 1), which is consistent with findings from other studies. ${ }^{13}$ Mean costs among newly diagnosed breast cancer patients were $\$ 58,615$ in the year following diagnosis.

\section{Model results}

The results of the model analyses comparing FFDM with FFDM + DBT are shown in Table 3. The patient population for the model analysis comprised 84,549 women aged 40-75 years in a one million member health plan who undergo mammography screening each year (Table 1). Both screening scenarios (ie, FFDM and FFDM + DBT) assumed that $100 \%$ of women used each respective modality; as such, 84,549 women utilizing FFDM were compared with exactly 84,549 women utilizing FFDM + DBT. With the base-case assumption that the FFDM rate of follow-up services is $15.35 \%$, and that with the greater predictive value afforded by FFDM + DBT decreasing this rate to the ACR and AHRQ benchmark of $10 \%, 4,523$ women in the hypothetical health plan who are screened with FFDM + DBT avoid use of follow-up services such as additional imaging and biopsy. Total annual cost savings to the health plan are \$2.4 million, comprising $\$ 5.5$ million savings from avoiding follow-up services and $\$ 1.2$ million from earlier detection of breast cancer, both of which more than offset the incremental cost of $\$ 4.2$ million by adding DBT to screening. Cost estimates are also shown in Table 3 on a per patient basis (ie, total costs divided by the number of women screened). In the base-case scenario, annual per patient cost savings due to use of DBT are $\$ 28.53$. On a per member per month basis (ie, cost savings realized by the hypothetical health plan each month across all of its one million members), cost savings due to use of DBT are $\$ 0.20$.
Adjusting the base-case rate of FFDM + DBT follow-up services of $10 \%$ across a range encompassing $8 \%-12 \%$ has an appreciable impact on the analysis results. As would be expected, transitioning lower than the ACR and AHRQ benchmark of $10 \%$ for follow-up services yields even greater cost savings. Whereas the base-case per patient cost savings assuming an incremental reimbursement of \$50 were $\$ 28.53$, moving the rate to $9 \%$ or $8 \%$ yields net cost savings of $\$ 40.58$ and $\$ 52.64$, respectively. Conversely, per patient cost savings decrease to $\$ 16.48$ and $\$ 4.43$ for more modest rates of $11 \%$ and $12 \%$, respectively. Similar dynamics can be observed for the other metrics shown in Table 3.

\section{Discussion}

The results of this study demonstrate clinical and economic favorability for DBT in breast cancer screening among commercially-insured US women. Using a hypothetical incremental reimbursement of $\$ 50$ for DBT, cost savings from use of DBT amount to $\$ 2.4$ million per year for the hypothetical million member health plan in our base-case analyses. This translates to $\$ 28.53$ savings per screened patient, or $\$ 0.20$ savings per member per month across the plan population. These results are supported by the strength of the underlying clinical publications and administrative claims database utilized, which contains health care information on over 30 million patients per year. As such, the parameters of our model and the analysis results generated by them are robust, and these results should be generalizable to commercially-insured women in the US health system.

Mammography practices differ from institution to institution, and subjective decisions about recalling women for follow-up imaging and diagnostic services after their initial mammogram vary widely, even among individual radiologists and diagnosticians working within particular institutions. ${ }^{40,41}$ This analysis provides a range of results estimates to account for some of this variability. However, using a conservative estimate that one half of the approximately 39 million mammograms performed annually in the US are for screening (excluding Veterans Administration facilities), ${ }^{42}$ then a crude extrapolation of our estimated per patient net cost savings of $\$ 28.53$ suggests that use of DBT could account for over $\$ 550$ million saved annually in US breast cancer health care spending if DBT were reimbursed at a rate of $\$ 50$ more than FFDM. This potential cost saving is noteworthy, given that the aggregate cost of mammography screening in the USA is approximately $\$ 8$ billion per year. ${ }^{43}$

In addition to cost savings from reduced unnecessary resource utilization following a screening mammogram, 


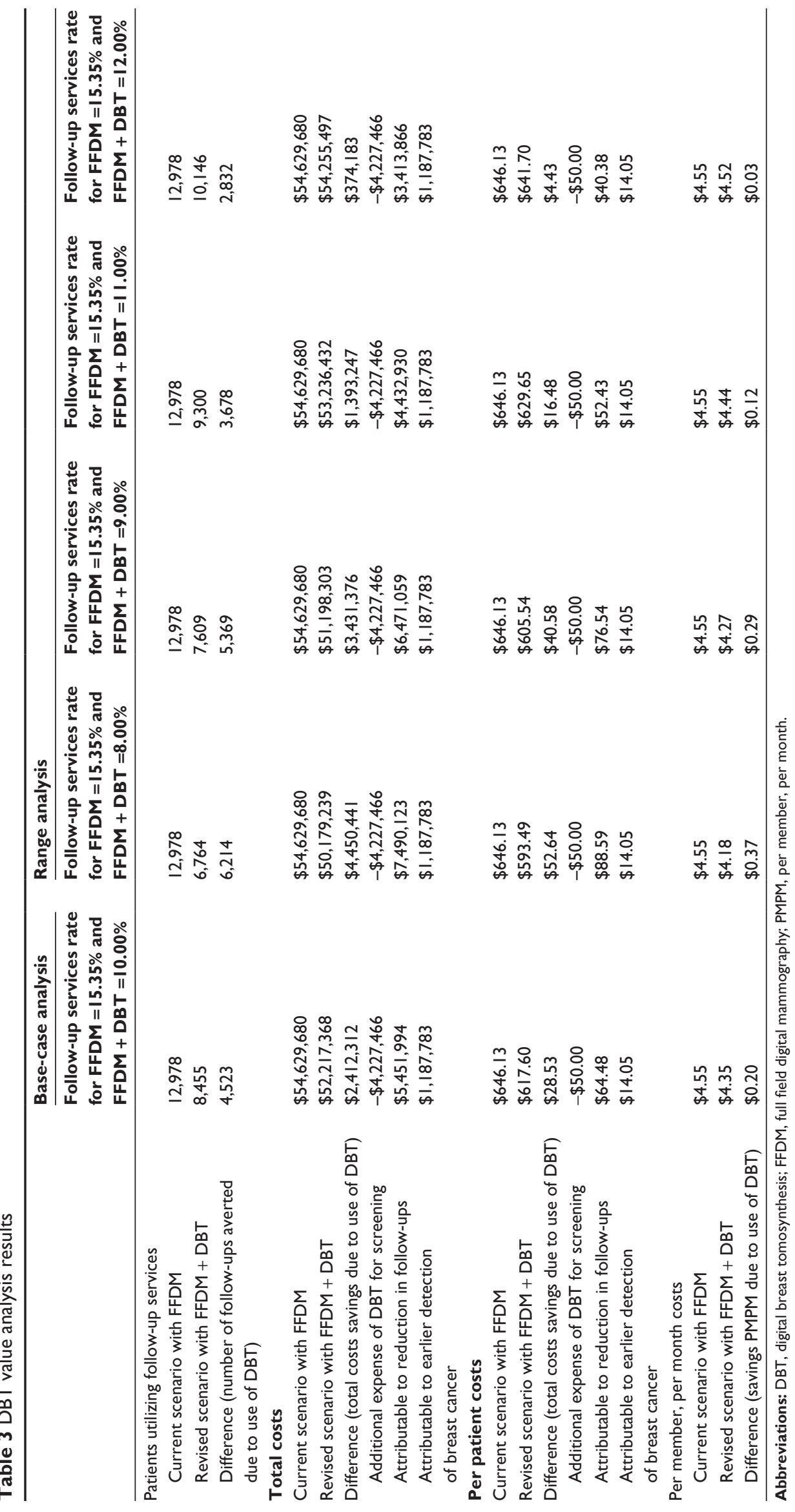


the reduction in follow-up services can have a substantial humanistic impact. Using a hypothetical 1 million member health plan, this analysis found that FFDM + DBT would cause 4,500 women to avoid unnecessary testing and/or treatment and the associated traumatic psychosocial experience of a false-positive screening mammogram. ${ }^{44,45}$ Numerous quantitative studies have been published measuring psychological and social aspects related to false-positive mammograms. ${ }^{46-48}$ These consequences and associated costs are not included in this current analysis. Furthermore, we did not account for costs associated with patients themselves, such as direct costs of copayments, coinsurance, and deductibles, and the indirect costs of transportation to and from medical appointments, work absence and lost productivity, and childcare coverage. ${ }^{49}$

Literature describing the potential value of DBT (ie, its comparative costs, cost-effectiveness, budget impact) is limited. A 2012 conference presentation by Kalra et $\mathrm{al}^{28}$ reported cost-effectiveness analyses of mammographic screening using DBT based on direct radiology costs resulting from differences in the recall rate observed at one institution over a 12-month period. The results suggested a direct cost savings of $\$ 10.19$ per woman screened (not including an incremental cost of the DBT examination), which is about one third of our base-case estimate of $\$ 28.53$. The difference between our analysis and the previous work of Kalra et al is likely due to the respective study designs and data. Specifically, the previous study by Kalra et al used 2011 Medicare reimbursement rates to estimate costs for all patients (including non-Medicare patients), excluded some diagnostic costs outside of radiology (eg, open biopsy), and did not account for cost savings due to earlier cancer detection. A follow-on study by Kalra et $\mathrm{a}^{29}$ confirmed findings from their first study, with DBT screening decreasing the overall costs of unnecessary diagnostic workups by $17.1 \%$.

The cost of follow-up services due to abnormal screening results is a core component when analyzing the added value of DBT. Our estimate of $\$ 1,205.29$ contributes to a substantial gap in the literature necessary for better understanding the full economic consequences and cost-effectiveness of mammography screening paradigms. To our knowledge, only one comparable study describing the cost of follow-up services has been published in the past 10 years; Chubak et $\mathrm{al}^{50}$ estimated $\$ 527$ (2007 USD) as the cost of breast care following a false-positive mammogram in one Washington State health plan using 2007 Medicare reimbursement rates. The analysis time frame, data source, and cost estimation techniques (ie, Medicare fee schedule versus adjudicated commercial claims) likely all contribute to the differences in follow-up services costs observed by Chubak et al and our own estimates presented here.

Some evidence exists that tomosynthesis may not only affect the rate at which women are called back for additional services, but that it also affects the utilization rate of specific additional services. For example, Philpotts et $\mathrm{al}^{51}$ report that DBT expedites patient diagnostic workup and results in better patient throughput and resource utilization. Greenberg et $\mathrm{al}^{26}$ reported that $50 \%$ fewer diagnostic views were used for women who had cancer detected with combined DBT + FFDM examinations when compared with similar women for whom FFDM alone was used. As more is learned about the potential for DBT to streamline diagnostic pathways, it is possible that additional cost savings not included in our current analysis will be identified.

This analysis is subject to several limitations. First, we point out that the way we defined women recalled for additional follow-up imaging and diagnostic testing services closely approximates the BI-RADS definitions of recall, but there may have been a small number of women who were in fact recalled but went directly to magnetic resonance imaging, biopsy, or fine needle aspiration without diagnostic imaging. Also, in somewhat rare circumstances, women undergoing screening ultrasound following a screening mammogram (due to dense breast tissue) may have been misclassified as recalls, which could have artificially inflated the rate we report for women utilizing follow-up services. Another limitation of this study is that the data source used for the analysis includes women with commercial health insurance and may not be representative of women with other forms of health insurance (eg, Medicaid, full Medicare) or the uninsured. Additionally, the evidence demonstrating the clinical benefits of DBT, which serves as a foundation of this model, is based on studies performed on the only DBT system which was commercially available at the time of this analysis (Selenia Dimensions breast tomosynthesis system). Thus, this analysis may not be applicable to other systems for which limited clinical evidence currently exists.

Finally, we note that our estimate of the average annual mammography screening rate of $35.5 \%$ (Table 1) is lower than the rate of $50.8 \%$ reported by the ACS based on National Health Interview Survey data. ${ }^{52}$ We counter that self-reported screening behaviors from national surveys like the National Health Interview Survey often overestimate screening utilization, ${ }^{53}$ whereas the data underlying our analyses reflect actual real world screening utilization in a robust manner by tracking millions of women as they travel through the US health 
care system. Moreover, the ACS statistic pertains to women aged 40 years and older who had any mammogram in the past year (whether screening or diagnostic), whereas the rate we report specifically pinpoints screening mammography.

\section{Conclusion}

Use of DBT as a mammography screening modality substantially reduces the need for follow-up diagnostic services and improves detection of invasive cancers, allowing for earlier, less costly treatment. Results from our value analysis of DBT demonstrate that these beneficial attributes could translate into meaningful cost savings for US commercial health insurers. With approximately one in seven women receiving additional diagnostic imaging following digital screening mammography at an average cost of over $\$ 1,200$, and with the costs of breast cancer ranging with increasing stage from $\$ 35,000$ to $\$ 224,000$, wider adoption of DBT mammography presents a significant opportunity to deliver value-based care in the US health care system. Future research should evaluate the potential impact of DBT from the perspective of patients and/or other types of payers. Investigation of longer-term outcomes is also warranted to better understand the broader clinical and economic implications of adoption of DBT.

\section{Acknowledgment}

The authors appreciate the valuable contributions by Greg Lenhart and Jim Nelson toward development of the economic model reported in this paper.

\section{Disclosure}

Funding for this study was provided by Hologic, Inc. (Marlborough, MA, USA). The authors have no other relevant affiliations or financial involvement with any organization or entity with a financial interest in or financial conflict with the subject matter or materials discussed in the paper apart from those disclosed.

\section{References}

1. Siegel R, Ma J, Zou Z, Jemal A. Cancer statistics, 2014. CA Cancer J Clin. 2014;64(1):9-29.

2. Howlader N, Noone AM, Krapcho M, et al, editors. SEER Cancer Statistics Review, 1975-2011. Bethesda, MD, USA: National Cancer Institute; 2014. Available from: http://seer.cancer.gov/csr/1975_2011/. Accessed November 17, 2014.

3. Smith RA, Manassaram-Baptiste D, Brooks D, et al. Cancer screening in the United States, 2014: a review of current American Cancer Society guidelines and current issues in cancer screening. CA Cancer J Clin. 2014;64(1):30-51.

4. Berry DA, Cronin KA, Plevritis SK, et al; Cancer Intervention and Surveillance Modeling Network Collaborators. Effect of screening and adjuvant therapy on mortality from breast cancer. $N$ Engl J Med. 2005;353(17):1784-1792.
5. American Cancer Society. Breast Cancer Facts and Figures 2012 Atlanta, GA, USA: American Cancer Society Inc.; 2012. Available from: http://www.cancer.org/research/cancerfactsfigures/cancerfactsfigures/ cancer-facts-figures-2012. Accessed October 16, 2014.

6. American Cancer Society. Guidelines for the early detection of cancer. Available from: http://www.cancer.org/healthy/ findcancerearly/cancerscreeningguidelines/american-cancer-societyguidelines-for-the-early-detection-of-cancer. Accessed October 16, 2014.

7. American College of Obstetricians and Gynecologists. Practice bulletin no 122: breast cancer screening. Obstet Gynecol. 2011;118(2 Pt 1): 372-382.

8. Smith RA, Saslow D, Sawyer KA, et al; American Cancer Society High-Risk Work Group; American Cancer Society Screening Older Women Work Group; American Cancer Society Mammography Work Group; American Cancer Society Physical Examination Work Group; American Cancer Society New Technologies Work Group; American Cancer Society Breast Cancer Advisory Group. American Cancer Society guidelines for breast cancer screening: update 2003. CA Cancer J Clin. 2003;53(3):141-169.

9. Nelson HD, Tyne K, Naik A, et al. Screening for Breast Cancer: Systematic Evidence Review Update for the US Preventive Services Task Force. Evidence Review Update No 74. AHRQ Publication No 10-05142-EF-1. Rockville, MD, USA: Agency for Healthcare Research and Quality; 2009. Available from: http://www.ncbi.nlm.nih.gov/books/ NBK36392/. Accessed October 16, 2014.

10. American Cancer Society. Breast Cancer Facts and Figures 2013-2014. Atlanta, GA, USA: American Cancer Society Inc.; 2013. Available from: http://www.cancer.org/acs/groups/content/@research/documents/ document/acspc-042725.pdf. Accessed October 16, 2014.

11. Hubbard RA, Zhu W, Horblyuk R, et al. Diagnostic imaging and biopsy pathways following abnormal screen-film and digital screening mammography. Breast Cancer Res Treat. 2013;138(3):879-887.

12. Newman L. IOM report sets policy priorities for improving breast cancer screening. J Natl Cancer Inst. 2001;93(8):574-575.

13. Rosenberg RD, Yankaskas BC, Abraham LA, et al. Performance benchmarks for screening mammography. Radiology. 2006;241(1):55-66.

14. Schell MJ, Yankaskas BC, Ballard-Barbash R, et al. Evidence-based target recall rates for screening mammography. Radiology. 2007;243(3): 681-689.

15. Agency for Healthcare Research and Quality (AHRQ). Imaging efficiency: percentage of patients with mammography screening studies that are followed by a diagnostic mammography, ultrasound or MRI of the breast in an outpatient or office setting within 45 days. Measure Summary NQMC-8949. May 7, 2014. Available from: http:// www.qualitymeasures.ahrq.gov/content.aspx?id=47053. Accessed October 16,2014.

16. Rauscher GH, Murphy AM, Orsi JM, Dupuy DM, Grabler PM, Weldon CB. Beyond the mammography quality standards act: measuring the quality of breast cancer screening programs. AJR Am J Roentgenol. 2014;202(1):145-151.

17. Smith A. Tomosynthesis: the use of breast tomosynthesis in a clinical setting. White paper WP-00060 Rev 002, June 2012. Bedford, MA, USA: Hologic, Inc.; 2012. Available from: http://www.breasttomo.com/ sites/default/files/010-WP-00060-Rev2_June2012-TomoWhitePaper. pdf. Accessed October 16, 2014.

18. US Food and Drug Administration. Selenia Dimensions 3D System-P080003. Available from: http://www.fda.gov/medicaldevices/ productsandmedicalprocedures/deviceapprovalsandclearances/ recently-approveddevices/ucm246400.htm. Accessed October 16, 2014.

19. Smith A. Full-field breast tomosynthesis. Radiol Manage. 2005;27(5):25-31.

20. Destounis S, Arieno A, Morgan R. Initial experience with combination digital breast tomosynthesis plus full field digital mammography or full field digital mammography alone in the screening environment. J Clin Imaging Sci. 2014;4:9. 
21. Skaane P, Bandos AI, Gullien R, et al. Comparison of digital mammography alone and digital mammography plus tomosynthesis in a population-based screening program. Radiology. 2013;267(1):47-56.

22. Ciatto S, Houssami N, Bernardi D, et al. Integration of $3 D$ digital mammography with tomosynthesis for population breast-cancer screening (STORM): a prospective comparison study. Lancet Oncol. 2013;14(7): 583-589.

23. Rose SL, Tidwell AL, Bujnoch LJ, Kushwaha AC, Nordmann AS, Sexton R Jr. Implementation of breast tomosynthesis in a routine screening practice: an observational study. AJR Am J Roentgenol. 2013;200(6): 1401-1408.

24. Haas BM, Kalra V, Geisel J, Raghu M, Durand M, Philpotts LE. Comparison of tomosynthesis plus digital mammography and digital mammography alone for breast cancer screening. Radiology. 2013;269(3):694-700.

25. Conant E, Wan F, Thomas M, et al. Implementing digital breast tomosynthesis (DBT) in a screening population: PPV1 as a measure of outcome. Abstract presented at the Radiological Society of North America Scientific Assembly and Annual Meeting, Chicago, IL, USA, December 1-6, 2013. Available from: http://www2.rsna.org/timssnet/ rsna/media/pr2013/Conant/abstract/Conant-Tomosynthesis-AbstractLH.pdf. Accessed October 16, 2014.

26. Greenberg JS, Javitt MC, Katzen J, Michael S, Holland AE. Clinical performance metrics of $3 \mathrm{D}$ digital breast tomosynthesis compared with 2D digital mammography for breast cancer screening in community practice. AJR Am J Roentgenol. 2014;203(3):687-693.

27. Friedewald SM, Rafferty EA, Rose SL, et al. Breast cancer screening using tomosynthesis in combination with digital mammography. JAMA. 2014;311(24):2499-2507.

28. Kalra V, Haas B, Forman H, Philpotts L. Cost-effectiveness of digital breast tomosynthesis. Abstract presented at the Radiological Society of North America Scientific Assembly and Annual Meeting, Chicago, IL, USA, November 25-30, 2012. Available from: http://archive.rsna. org/2012/12043617.html. Accessed October 16, 2014.

29. Kalra V, Haas B, Philpotts L. Cost-effectiveness of tomosynthesis in screening mammography: analysis by breast density and patient age. Abstract presented at the Radiological Society of North America Scientific Assembly and Annual Meeting, Chicago, IL, USA, December 1-6, 2013. Available from: http://archive.rsna.org/2013/13044485.html. Accessed October 16, 2014.

30. Elmore JG, Nakano CY, Koepsell TD, Desnick LM, D’Orsi CJ, Ransohoff DF. International variation in screening mammography interpretations in community-based programs. J Natl Cancer Inst. 2003;95(18):1384-1393.

31. Truven Health Analytics, Inc. Truven Health Analytics MarketScan ${ }^{\circledR}$ Research Databases. Available from: http://truvenhealth.com/yourhealthcare-focus/analytic-research/marketscan-research-databases. Accessed October 16, 2014

32. Bonafede MM, Miller JD, Lenhart GM, Nelson J, Fajardo LL. Health insurer burden of patient recall following breast cancer screening mammography. Value Health. 2014;17(3):A82.

33. Tice JA, Ollendorf DA, Lee JM, Pearson SD. The comparative clinical effectiveness and value of supplemental screening test following negative mammography in women with dense breast tissue. California Technology Assessment Forum. San Francisco, CA, USA: California Technology Assessment Forum; November 4, 2013. Available from: http://www.ctaf.org/sites/default/files/assessments/ctaf-final-reportdense-breast-imaging-11.04.2013-b.pdf. Accessed October 16, 2014.

34. Sickles EA, D’Orsi CJ, Bassett LW, et al. ACR BI-RADS ${ }^{\circledR}$ mammography. In: ACR BI-RADS $S^{\circledR}$ Atlas, Breast Imaging Reporting and Data System. Reston, VA, USA: American College of Radiology; 2013.

35. Partridge AH, Hughes ME, Ottesen RA, et al. The effect of age on delay in diagnosis and stage of breast cancer. Oncologist. 2012;17(6): $775-782$.
36. Skaane P, Bandos AI, Gullien R, et al. Prospective trial comparing fullfield digital mammography (FFDM) versus combined FFDM and tomosynthesis in a population-based screening programme using independent double reading with arbitration. Eur Radiol. 2013;23(8):2061-2071.

37. Mittmann N, Isogai PK, Saskin R, et al. Population-based health care cost estimates related to breast cancer by staging. J Clin Oncol. 2011; 29 Suppl 15:6108.

38. Legorreta AP, Brooks RJ, Leibowitz AN, Solin LJ. Cost of breast cancer treatment. A 4-year longitudinal study. Arch Intern Med. 1996;156(19): 2197-2201.

39. Lindfors KK, McGahan MC, Rosenquist CJ, Hurlock GS. Computer-aided detection of breast cancer: a cost-effectiveness study. Radiology. 2006;239(3):710-717.

40. Elmore JG, Gross CP. The cost of breast cancer screening in the United States: a picture is worth ... a billion dollars? Ann Intern Med. 2014;160(3):203

41. Barlow WE, Chi C, Carney PA, et al. Accuracy of screening mammography interpretation by characteristics of radiologists. $J$ Natl Cancer Inst. 2004;96(24): 1840-1850.

42. US Food and Drug Administration. Mammography Quality Standards Act and Program, National Statistics. Total annual mammography procedures reported, as of June 1, 2014. Available from: http://www.fda.gov/RadiationEmittingProducts/MammographyQualityStandardsActandProgram/ FacilityScorecard/ucm113858.htm. Accessed October 16, 2014.

43. O'Donoghue C, Eklund M, Ozanne EM, Esserman LJ. Aggregate cost of mammography screening in the United States: comparison of current practice and advocated guidelines. Ann Intern Med. 2014;160(3): 145.

44. Brodersen J, Jørgensen KJ, Gøtzsche PC. The benefits and harms of screening for cancer with a focus on breast screening. Pol Arch Med Wewn. 2010;120(3):89-94.

45. Brodersen J, Siersma VD. Long-term psychosocial consequences of false-positive screening mammography. Ann Fam Med. 2013;11(2): 106-115.

46. Salz T, Richman AR, Brewer NT. Meta-analyses of the effect of falsepositive mammograms on generic and specific psychosocial outcomes. Psychooncology. 2010;19(10):1026-1034.

47. Bond M, Pavey T, Welch K, et al. Systematic review of the psychological consequences of false-positive screening mammograms. Health Technol Assess. 2013;17(13):1-170, v-vi.

48. Harvey SC, Vegesna A, Mass S, Clarke J, Skoufalos A. Understanding patient options, utilization patterns, and burdens associated with breast cancer screening. J Womens Health (Larchmt). 2014;23 Suppl 1: S3-S9.

49. Alcusky M, Philpotts L, Bonafede M, Clarke J, Skoufalos A. The patient burden of screening mammography recall. JWomens Health (Larchmt). 2014;23 Suppl 1:S11-S19.

50. Chubak J, Boudreau DM, Fishman PA, Elmore JG. Cost of breast-related care in the year following false positive screening mammograms. Med Care. 2010;48(9):815-820.

51. Philpotts L, Kalra V, Crenshaw J, Butler R. How tomosynthesis optimizes patient work up, throughput, and resource utilization. Abstract presented at the Radiological Society of North America Scientific Assembly and Annual Meeting, Chicago, IL, USA, December 1-6, 2013. Available from: http://archive.rsna.org/2013/13016543.html. Accessed October $16,2014$.

52. American Cancer Society. Cancer Prevention and Early Detection Facts and Figures 2013. Atlanta, GA, USA: American Cancer Society; 2013. Available from: http://www.cancer.org/acs/groups/content/@epidemiologysurveilance/documents/document/acspc-037535.pdf. Accessed October 16, 2014.

53. Cronin KA, Miglioretti DL, Krapcho M, et al. Bias associated with selfreport of prior screening mammography. Cancer Epidemiol Biomarkers Prev. 2009;18(6):1699-1705. 


\section{Publish your work in this journal}

ClinicoEconomics \& Outcomes Research is an international, peerreviewed open-access journal focusing on Health Technology Assessment, Pharmacoeconomics and Outcomes Research in the areas of diagnosis, medical devices, and clinical, surgical and pharmacological intervention. The economic impact of health policy and health systems organization also constitute important areas of coverage. The manuscript management system is completely online and includes a very quick and fair peer-review system, which is all easy to use. Visit http://www.dovepress.com/testimonials.php to read real quotes from published authors.

Submit your manuscript here: http://www.dovepress.com/clinicoeconomics-and-outcomes-research-journal 